\title{
Serum DKK-1 level in the development of ankylosing spondylitis and rheumatic arthritis: a meta-analysis
}

\author{
Li Zhang ${ }^{1,2}$, Hui Ouyang ${ }^{1}$, Zhen $\mathrm{Xie}^{3}$, Zhi-Hui Liang ${ }^{1}$ and Xiong-Wen $\mathrm{Wu}^{1}$
}

To explore the association of serum Dickkopf-1 (DKK-1) levels with the development of ankylosing spondylitis (AS) and rheumatic arthritis (RA) in humans, databases including PubMed, EBSCO, Springerlink, Ovid, WANFANG and China National Knowledge Infrastructure (CNKI) were searched to identify relevant studies. On the basis of rigorous inclusion and exclusion criteria, case-control studies of the relationships between serum DKK-1 levels and AS and RA published before December 2014 were enrolled. Statistical analyses were performed using Comprehensive Meta-analysis 2.0 (CMA 2.0). Seven case-control trials with a total of 300 AS patients, 136 RA patients and 232 healthy controls were included in this study. Meta-analysis results revealed that DKK-1 serum levels were significantly higher in AS patients than in normal controls (standard mean differences (s.m.d.) $=0.301,95 \%$ confidence interval $(\mathrm{Cl})=0.094-0.507, P=0.004)$, whereas no significant difference in DKK-1 serum levels was observed between RA patients and healthy controls (s.m.d. $=0.798,95 \% \mathrm{Cl}=-2.166-3.763, P=0.598$ ). Serum DKK-1 level may be closely related to the development of AS but not of RA.

Experimental \& Molecular Medicine (2016) 48, e228; doi:10.1038/emm.2016.12; published online 22 April 2016

\section{INTRODUCTION}

Ankylosing spondylitis (AS), previously known as MarieStrümpell disease or Bechterew's syndrome, has been identified as an example of both inflammatory and autoimmune spondyloarthropathy. ${ }^{1}$ Its initial effect on sacroiliac joints is a hallmark of AS. Subsequently, it involves spine joints, where ankyloses develops, and eventually invades the axial skeleton, leading to complete fusion and rigidity of the spine. ${ }^{2,3}$ AS may be clinically present with physical manifestations such as stiffness, sleep disturbances and decreased spinal mobility, as well as psychological outcomes, including stress, anxiety and depression. ${ }^{4}$ Rheumatoid arthritis (RA), a chronic inflammatory autoimmune disease, is characterized by consistent synovitis, causing the destruction of cartilage and bone, and leading to deformity in multiple joints. ${ }^{5} \mathrm{RA}$ is also characterized by hyperplasia, autoantibody production (particularly anti-citrullinated protein and rheumatoid factor antibodies), and systemic features, including cardiovascular, pulmonary, psychological and skeletal disorders, among which chronic inflammation and bone erosion are most common. ${ }^{6,7}$ Accumulating evidence suggests that the AS and RA pathologies are multifactorial, and the interaction of various environmental factors such as humid and cold climates and inherited risks contribute to them. ${ }^{8-10}$ Apart from the well-known AS- and RA-related HLA-B27 antigen, other proteins, including Dickkopf-1 (DKK-1) protein, have been implicated in the etiology of AS and RA. ${ }^{11-13}$

DKK-1, belonging to the Dickkopf family, is a secreted molecule consisting of a signal peptide sequence and two cysteine-rich domains. It participates in the process of embryonic development and acts as an endogenous inhibitor modulating the Wnt/ $\beta$-catenin signaling pathways. ${ }^{14,15}$ After binding to low-density lipoprotein receptor-related protein$5 / 6(\mathrm{LRP} 5 / 6)$ and the frizzled receptor, Wnt-1 protein is capable of signaling proliferation through $\beta$-catenin. ${ }^{16,17}$ DKK- 1 binds to LRP5/6 and blocks contact between LRP5/6 and Wnt-1, leading to $\beta$-catenin degradation and proliferation retardation. ${ }^{18}$ In several recent studies, serum DKK-1 levels have been reported to be involved in the etiology of AS and RA. ${ }^{11,19,20}$ Nevertheless, there also exist inconsistent findings regarding the relationship between serum DKK-1 level and the occurrence of AS and RA. ${ }^{21}$ Given these contradictory results, we performed the present metaanalysis to further explore the role of DKK-1 in the development of AS and RA.

\footnotetext{
${ }^{1}$ Department of Immunology, Tongji Medical College, Huazhong University of Science and Technology, Wuhan, China; ${ }^{2}$ Department of Neurology, The Central Hospital of Wuhan, Wuhan, China and ${ }^{3}$ Department of Otolaryngology, Union Hospital, Wuhan, China

Correspondence: Dr Z-H Liang or Dr X-W Wu, Department of Immunology, Tongji Medical College, Huazhong University of Science and Technology, Hangkong Road No. 13, Wuhan 430030, China.

E-mail: Zhihuiliang67@163.com or xiongwenwu@hotmail.com

Received 21 July 2015; revised 8 October 2015; accepted 27 October 2015
} 


\section{MATERIALS AND METHODS}

\section{Literature search and selection}

The present meta-analysis was conducted by following the Metaanalysis of Observational Studies in Epidemiology (MOOSE) group's guidelines. ${ }^{22}$ We performed a systematic search for studies published before December 2014 in the following electronic databases: PubMed, Embase, Web of Science, Springerlink, Ovid, Cochrane Library, EBSCO, WANFANG, VIP and China National Knowledge Infrastructure (CNKI). Keywords included ankylosing spondylitis, Bechterew's disease, rheumatoid spondylitis, DKK-1 and Dickkopf-1. We also reviewed references cited in these articles and manually searched related studies to identify additional relevant publications. The established study selection criteria included the following four aspects: the study was a case-control study; cases were patients with AS/RA and controls were healthy people, and all patients were mobility impaired with pain in joints, arthrofibrosis and bony ankyloses; the study provided complete data concerning DKK-1 serum levels in AS/RA patients and controls; and the study was published in English or Chinese. In the case of duplicate publications, we chose the one with the largest sample size or most recent publication date.

\section{Data extraction and quality assessment}

From identified studies, two researchers independently collected the following data: name of the first author, publication year, country of study, patient ethnicity, age and gender, disease studied, detection methods for DKK-1 serum level and so on. Disagreements about study inclusion were resolved by discussion with a third reviewer until a consensus was reached for each study. To assess study quality, two authors applied a set of predefined criteria based on the Critical Appraisal Skill Program's (CASP) criteria (http://www.casp-uk.net/).

\section{Statistical analysis}

Statistical analyses were performed using the Comprehensive Metaanalysis 2.0 software (CMA 2.0). The standard mean differences (s.m.d.) with 95\% confidence intervals (CIs) were calculated to explore the association of serum DKK-1, and AS and RA through either fixed-effects or random-effects models. The significance of the overall effect sizes (s.m.d.'s) was evaluated with $Z$-tests. Cochran's Q statistic and $I^{2}$ tests were used to detect heterogeneity across studies. Random-effects models were applied in the case of significant heterogeneity $\left(P<0.05\right.$ or $I^{2}$ test $\left.>50 \%\right)$; otherwise, fixed-effects models were utilized. ${ }^{23,24}$ To determine the influence of heterogeneity, univariate and multivariate meta-regression analyses were adopted. Further investigation was conducted using Monte Carlo methods. To assess the impact of each study on the overall result, a sensitivity analysis was conducted. To detect publication bias among the included studies, funnel plots, the classic fail-safe $\mathrm{N}$ and Egger's linear regression test were used. The significance level was set at $P<0.05$.

\section{RESULTS}

\section{The baseline characteristics of included studies}

From the 38 articles retrieved initially, we excluded duplicates $(n=6)$, letters, reviews or meta-analyses $(n=4)$, non-human studies $(n=2)$ and studies irrelevant to the study topic $(n=6)$. In the final meta-analysis, we focused on seven case-control studies, ${ }^{11,19,25-28}$ published between 2010 and 2012, which contained 300 AS patients, 136 RA patients and 232 healthy controls. In six trials, the subjects were Asian; in the last study, the subjects were Caucasian.

a

DKK-1 serum level

(AS VS. Control)

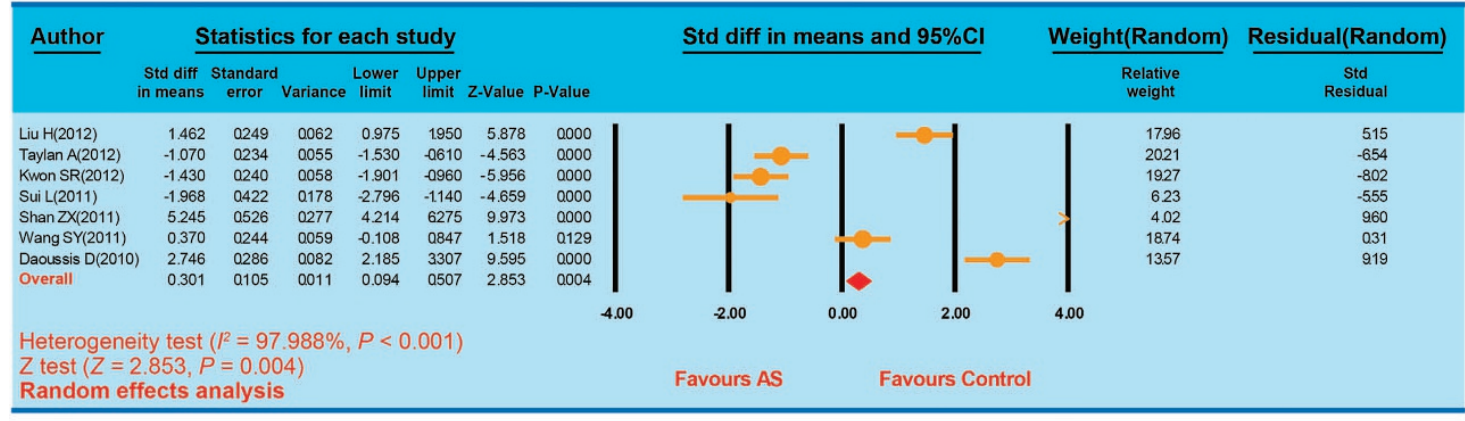

b

DKK-1 serum level

(RA VS. Control)

\begin{tabular}{|c|c|c|c|c|c|c|c|c|c|c|}
\hline Author & \multicolumn{6}{|c|}{ Statistics for each study } & & Std diff in means and $95 \% \mathrm{Cl}$ & $\frac{\text { Weight(Random) }}{\begin{array}{c}\text { Relative } \\
\text { weight }\end{array}}$ & $\frac{\text { Residual(Random) }}{\begin{array}{c}\text { Std } \\
\text { Residual }\end{array}}$ \\
\hline Suil L(2011) & 0.130 & 0.349 & 0.122 & -0.554 & 0.814 & 0.373 & 0.709 & & 25.07 & .0 .26 \\
\hline Wang SY(2011) & 1.050 & 0.257 & 0.066 & 0.546 & 1.554 & 4.080 & 0.000 & C. & 2522 & 0.10 \\
\hline Daoussis D(2010) & -3.410 & 0.322 & 0.103 & -4.040 & -2.779 & -10.603 & 0.000 & - & 25.12 & -1.61 \\
\hline Overall & 0.798 & 1.513 & 2.288 & -2.166 & 3.763 & 0.528 & 0.598 & & & \\
\hline \multicolumn{11}{|c|}{ Heterogeneity test $\left(I^{2}=98.702 \%, P<0.001\right)$} \\
\hline \multicolumn{8}{|c|}{$\begin{array}{l}Z \text { test }(Z=0.528, P=0.598) \\
R \text { Random effects analysis }\end{array}$} & Favours Control & & \\
\hline
\end{tabular}

Figure 1 Forest plots based on serum Dickkopf-1 levels: (a) forest plot for the AS studies; (b) forest plot for the RA studies. AS, ankylosing spondylitis; RA, rheumatic arthritis. 
a

DKK-1 serum level

(AS VS. Control)

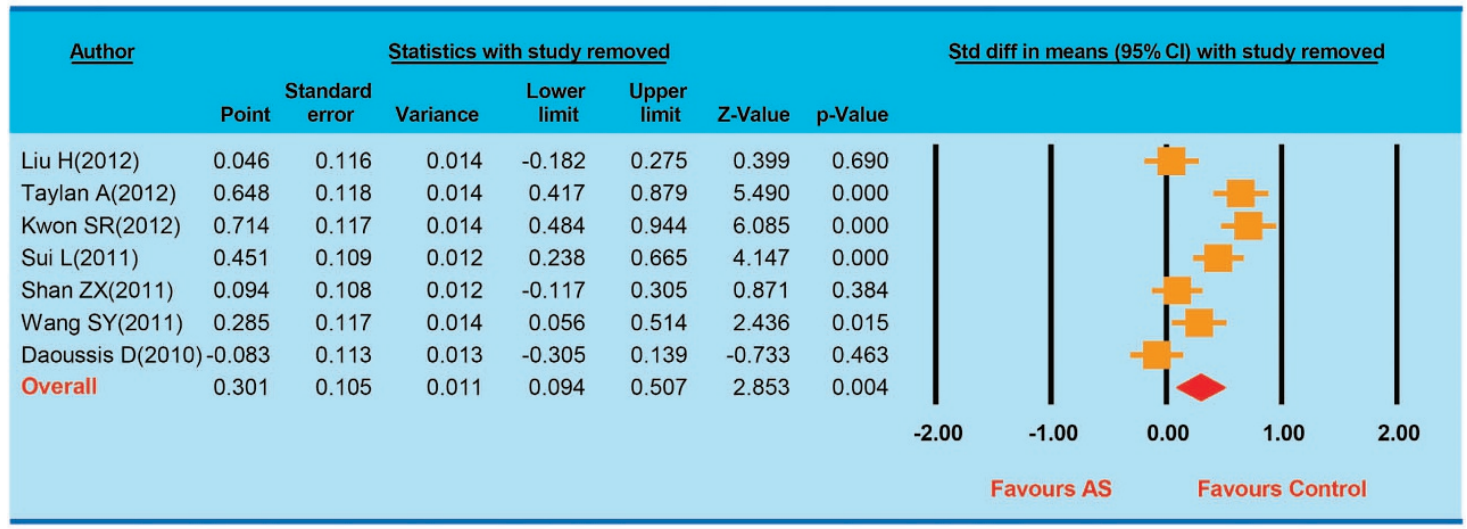

b

DKK-1 serum level

(RA VS. Control)

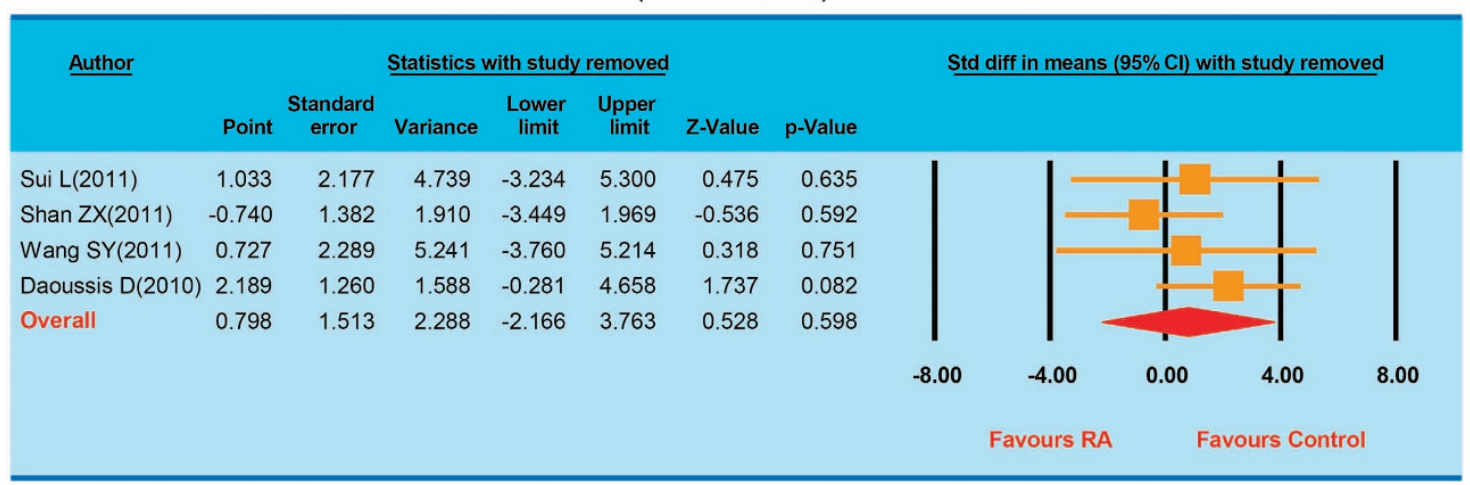

Figure 2 Sensitivity analyses: (a) sensitivity analyses for the AS studies; (b) sensitivity analyses for the RA studies. AS, ankylosing spondylitis; RA, rheumatic arthritis.

\section{Results of meta-analysis}

Seven trials investigated the association between DKK-1 serum levels and AS. Due to heterogeneity among the enrolled studies $(P<0.05)$, a random-effects model was used. Meta-analysis results revealed that DKK-1 serum levels were significantly higher in AS patients than in healthy controls (s.m.d. $=0.301$, 95\% CI $=0.094-0.507, P=0.004$ ) (Figure 1). Four trials reported on the association between DKK-1 serum levels and RA. Heterogeneity among the four studies necessitated a random-effects model $(P<0.05)$. Meta-analysis results revealed no significant differences between RA patients and healthy controls (s.m.d. $=0.798,95 \% \mathrm{CI}=-2.166-3.763, P=0.598$ ) (Figure 1).

\section{Sensitivity analysis and publication bias}

A sensitivity analysis indicated that four of the included studies would not affect the pooled effect sizes of the associations between serum DKK-1 levels, and AS and RA (Figure 2), but the other three trials would. ${ }^{11,25,27}$ A meta-regression analysis indicated that publication year, country, ethnicity and language were not potential sources of heterogeneity and did not affect the overall effect size (all $P>0.05$ ) (Figure 3). Funnel plots were symmetric, suggesting no publication bias in the enrolled studies, and the Egger linear regression analysis and classic fail-safe $\mathrm{N}$ confirmed that conclusion (all $P>0.05$; Figure 4).

\section{DISCUSSION}

The current meta-analysis explored studies that investigated the associations between DKK-1 serum levels, and AS and RA risk. The primary results of this meta-analysis demonstrated that serum DKK-1 levels in AS patients were higher than those in control subjects, indicating that elevated DKK-1 serum levels may be a risk factor for the occurrence and development of AS. DKK-1 serum levels may also serve as a helpful biomarker for the diagnosis of AS. However, no significant differences were found in DKK-1 expression between RA patients and healthy controls. So far, the precise mechanism by which DKK-1 affects the occurrence of AS remains unclear. It is widely accepted that DKK-1 levels accelerate the process of bone formation or resorption via the Wnt pathway, possibly accounting for its effect on AS development. ${ }^{11,29}$ DKK-1 could block the Wnt or $\beta$-catenin signaling pathway, which play an important role in the development of various diseases. ${ }^{30-32}$ It has been reported that Wnt proteins are involved in normal bone metabolism, various cell activities (including cell adhesion, migration, polarity), and particularly in osteoplastic 
a

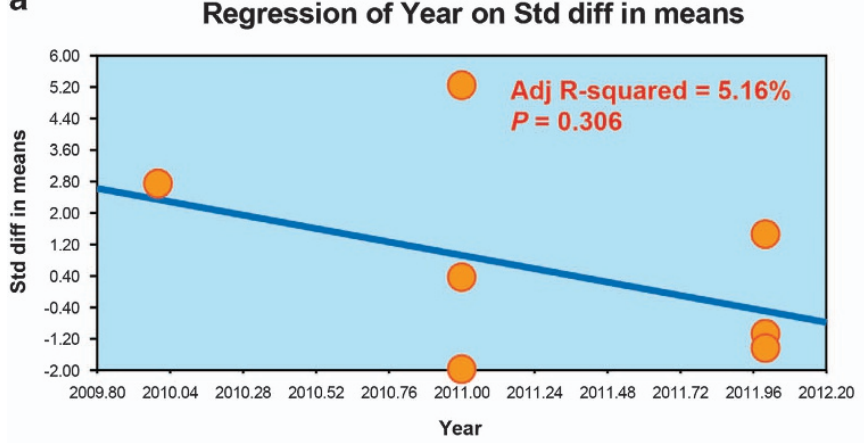

C

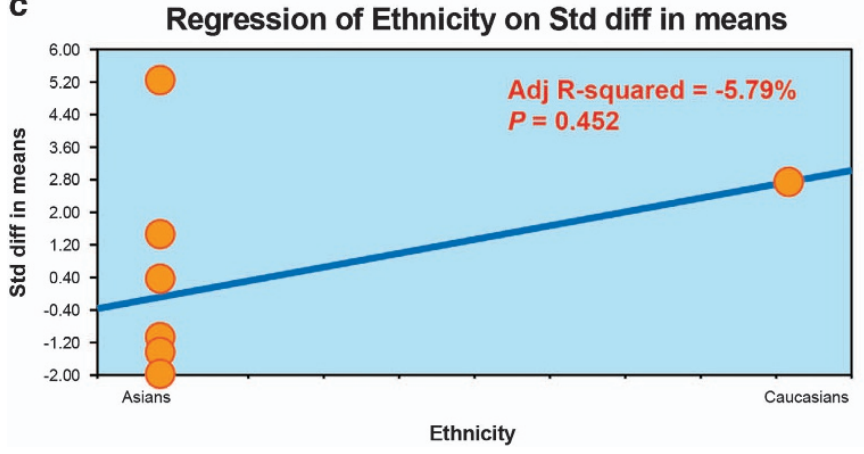

b

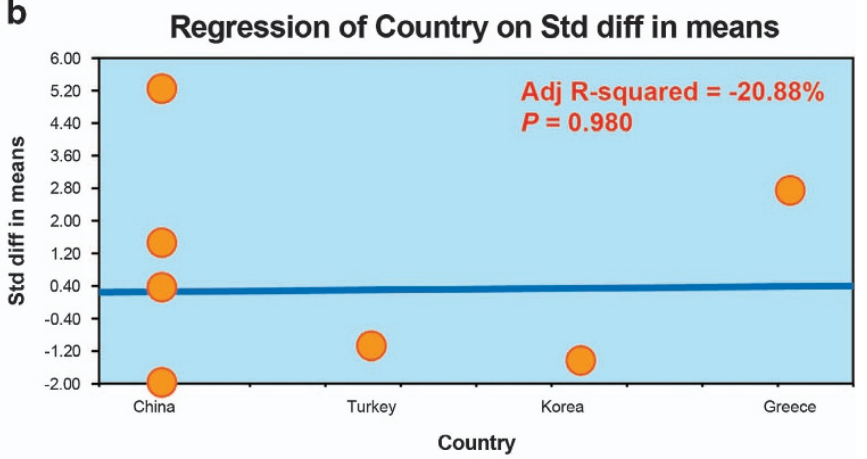

d

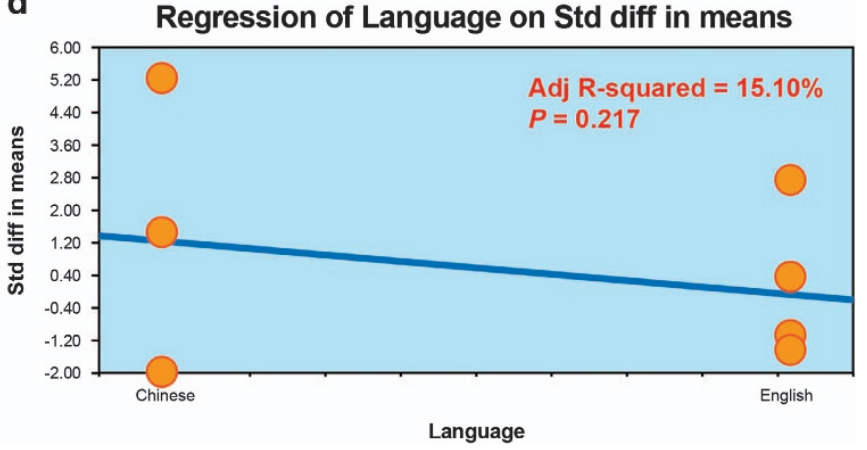

Figure 3 Meta-regression analyses presenting the sources of heterogeneity among the included studies: (a) meta-regression exploring the effect of publication year; (b) meta-regression exploring the effect of language; (c) meta-regression exploring the effect of country; (d) meta-regression exploring the effect of ethnicity.

formation. ${ }^{11,20}$ More precisely, DKK-1 may inhibit the Wnt signaling pathway by inducing the phosphorylation and degradation of $\beta$-catenin, which blocks the formation and differentiation of osteoblasts and induces the apoptosis of immature osteoblasts. ${ }^{19}$ It has also been reported that DKK-1 may inhibit osteoblasts, activate osteoclasts and disrupt the balance of ossification and osteolysis, which might increase the risk of AS and promote its progression. ${ }^{33}$ Some studies have previously suggested that increased serum levels of DKK-1 in bone marrow and peripheral blood are related to the occurrence of osteolytic bone lesions among AS patients. ${ }^{19,20}$ In this regard, DKK-1 expression in degenerative joint diseases or AS could inhibit bone formation in human joints, further exacerbating the bone resorption imbalance. ${ }^{30}$ In our study, we found that DKK-1 serum levels were significantly increased in AS patients, suggesting that elevated DKK-1 serum concentration is associated with an increased risk of AS. Likewise, Daoussis et al. ${ }^{11}$ also found that increased DKK-1 serum levels were related to increased AS risk and progression. However, they also found that binding of DKK-1 to the low-density lipoprotein receptor-related protein LRP-5/LRP-6, which inhibits binding of Wnt proteins to LRP-5/LRP-6, did not increase with DKK-1 levels. Current evidence suggests that AS progression involves cycles of bone resorption coupled with subsequent bone formation. ${ }^{34} \mathrm{~A}$ possible reason for the lack of a relationship between DKK-1 levels and binding of DKK-1 to LRP-6 is that DKK-1 not only serves as a suppressor of bone formation but also as a promoter of bone resorption.
According to work by Ahmed et al. ${ }^{35}$ DKK-1 could upregulate the expression of macrophage colony-stimulating factor, which would promote the production of osteoclast differentiation factor and increase osteoclasts' quantity and activity as well as subsequent bone resorption. Interestingly, our study found a relationship between DKK-1 and AS development, and our results indicate that $\mathrm{DKK}-1$ is potentially at least partially responsible for AS development via the Wnt signaling pathway. Nevertheless, limitations in the present study are also worth noting. First, our explanations of the study results mainly focus on the Wnt signaling pathway. However, these explanations should be considered preliminary and regarded with some degree of caution. The number of patients included in this analysis is relatively small, and thus we have no survival data to evaluate the prognosis of patients with AS. Therefore, larger clinical trials are warranted to more accurately and comprehensively explore the diagnosis and prognosis of AS and the pathophysiological role of DKK-1. More importantly, the baseline characteristics tables show that we chose to treat some RA patients as controls. However, because of our focus on AS, little attention was devoted to the exploration of DKK-1's role in RA. In addition, the included studies provided little information about factors that might affect serum DKK-1 levels, such as platelet-modifying drugs, and therefore we were unable to provide a more detailed investigation into the effects of these factors on the relationship between serum DKK-1 and AS. This omission may reduce the reliability of our study. 
a

a DKK-1 serum level

(AS VS. Control)

Funnel Plot of Precision by Std diff in means

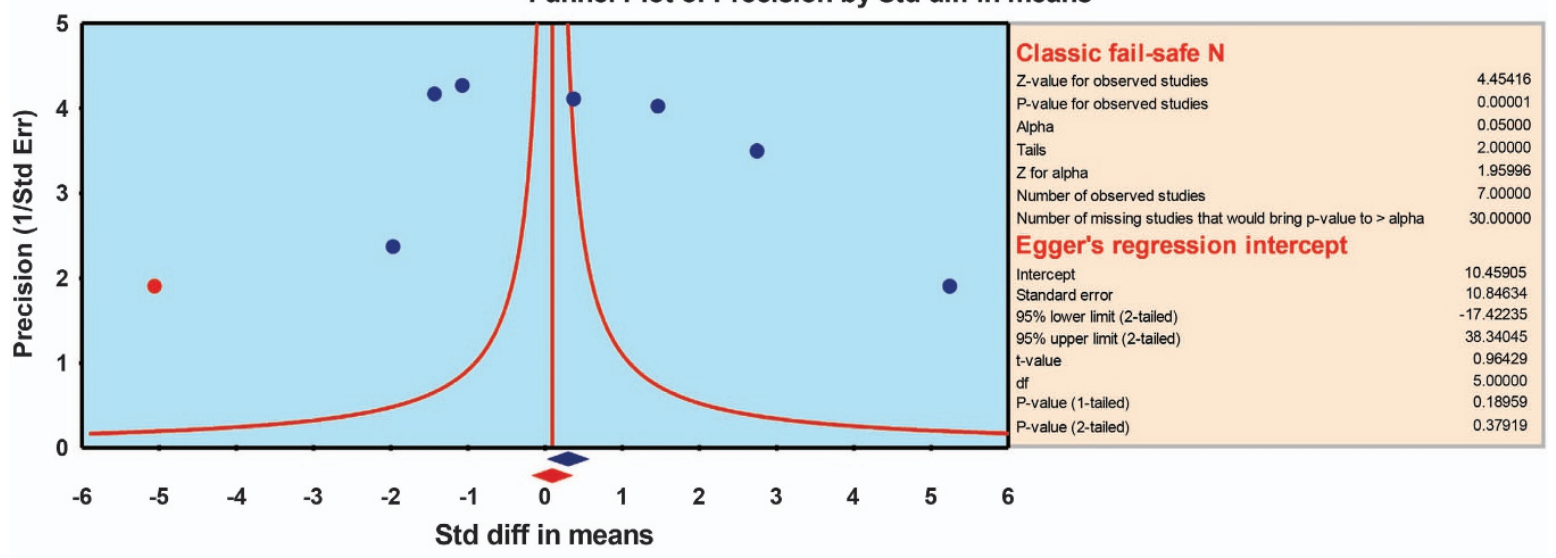

b

DKK-1 serum level

(RA VS. Control)

Funnel Plot of Precision by Std diff in means

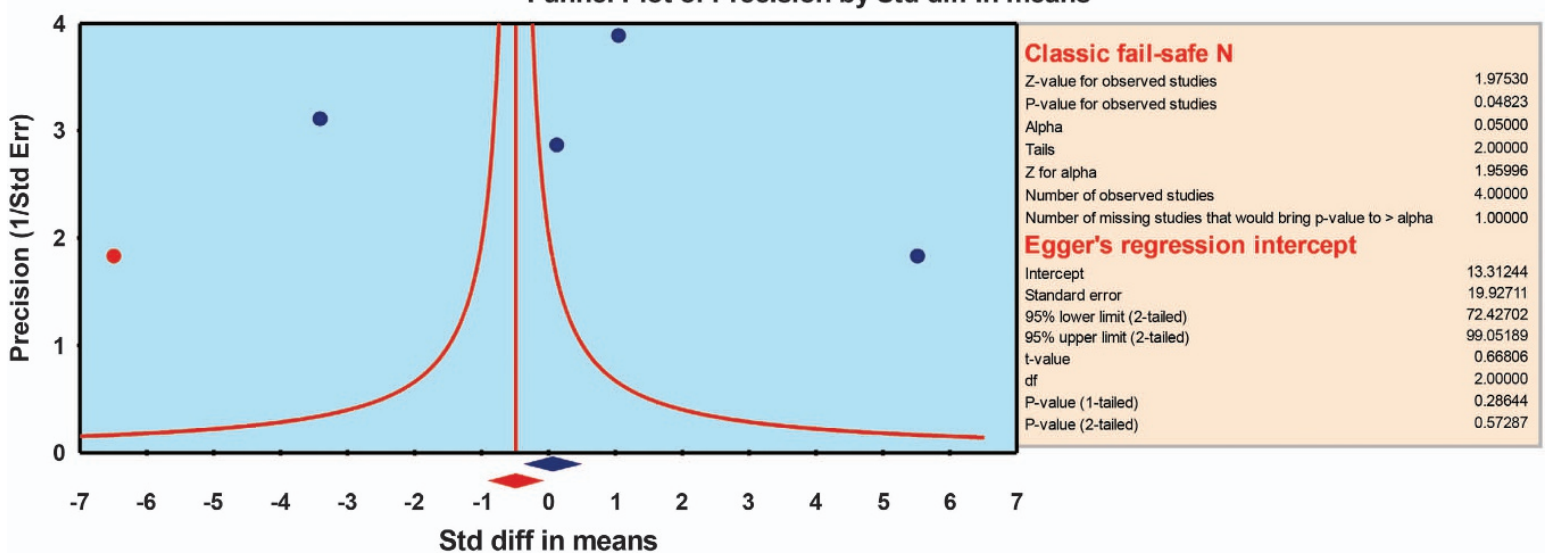

Figure 4 Tests of publication bias: (a) publication bias among the AS studies; (b) publication among the RA studies. AS, ankylosing spondylitis; RA, rheumatic arthritis.

Taken together, these data suggest that serum DKK-1 levels are elevated in AS patients compared with controls. Our results may eventually contribute to the development of novel treatments specifically designed to target bone formation in AS, an area that is currently underexplored. Further investigation of the function of DKK-1 in AS patients may be of great importance and may result in a deeper understanding of the molecular factors controlling the activation of the Wnt signaling pathways.

\section{CONFLICT OF INTEREST}

The authors declare no conflict of interest.

\section{ACKNOWLEDGEMENTS}

This project was supported by the National Natural Science Foundation of China: (no. 31370885). We acknowledge the reviewers for their helpful comments on this paper.
1 Chen WH, Yin HL, Lin HS, Chen CJ. Symptomatic noncompressive motoromyelopathy presents as early manifestation in ankylosing spondylitis. Rheumatol Int 2011; 31: 945-950.

2 Huang F, Gu J, Zhu P, Bao C, Xu J, Xu H et al. Efficacy and safety of adalimumab in chinese adults with active ankylosing spondylitis: results of a randomised, controlled trial. Ann Rheum Dis 2014; 73: 587-594.

3 Kassimos DG, Vassilakos J, Magiorkinis G, Garyfallos A. Prevalence and clinical manifestations of ankylosing spondylitis in young greek males. Clin Rheumatol 2014; 33: 1303-1306.

4 Baysal O, Durmus B, Ersoy Y, Altay Z, Senel K, Nas K et al. Relationship between psychological status and disease activity and quality of life in ankylosing spondylitis. Rheumatol Int 2011; 31: 795-800.

5 Song SN, Iwahashi M, Tomosugi N, Uno K, Yamana J, Yamana S et al. Comparative evaluation of the effects of treatment with tocilizumab and tnfalpha inhibitors on serum hepcidin, anemia response and disease activity in rheumatoid arthritis patients. Arthritis Res Ther 2013; 15: R141.

6 Mclnnes IB, Schett G. The pathogenesis of rheumatoid arthritis. N Eng/ J Med 2011; 365: 2205-2219.

7 Schett G, Gravallese E. Bone erosion in rheumatoid arthritis: Mechanisms, diagnosis and treatment. Nat Rev Rheumatol 2012; 8: 656-664.

8 Boonen A, Braun J, van der Horst Bruinsma IE, Huang F, Maksymowych W, Kostanjsek $\mathrm{N}$ et al. Asas/who icf core sets for ankylosing spondylitis (as): How to classify the impact of as on functioning and health. Ann Rheum Dis 2010; 69: 102-107. 
9 Costenbader KH, Gay S, Alarcon-Riquelme ME, laccarino L, Doria A. Genes, epigenetic regulation and environmental factors: which is the most relevant in developing autoimmune diseases? Autoimmun Rev 2012; 11: 604-609.

$10 \mathrm{Ma} \mathrm{B}$, Yang B, Guo H, Wang Y, Zhang D, Zhang Y et al. The association between tumor necrosis factor alpha promoter polymorphisms and ankylosing spondylitis: a meta-analysis. Hum Immunol 2013; 74: 1357-1362.

11 Daoussis D, Liossis SN, Solomou EE, Tsanaktsi A, Bounia K, Karampetsou $\mathrm{M}$ et al. Evidence that DKK-1 is dysfunctional in ankylosing spondylitis. Arthritis Rheum 2010; 62: 150-158.

12 Evans DM, Spencer CC, Pointon JJ, Su Z, Harvey D, Kochan G et al. Interaction between erap1 and hla-b27 in ankylosing spondylitis implicates peptide handling in the mechanism for hla-b27 in disease susceptibility. Nat Genet 2011; 43: 761-767.

13 Heiland GR, Appel H, Poddubnyy D, Zwerina J, Hueber A, Haibel H et al. High level of functional Dickkopf-1 predicts protection from syndesmophyte formation in patients with ankylosing spondylitis. Ann Rheum Dis 2012; 71: 572-574.

14 Makino T, Yamasaki M, Takemasa I, Takeno A, Nakamura Y, Miyata H et al. Dickkopf-1 expression as a marker for predicting clinical outcome in esophageal squamous cell carcinoma. Ann Surg Oncol 2009; 16: 2058-2064.

15 Li S, Qin X, Guo X, Cui A, He Y, Wei S et al. Dickkopf-1 is oncogenic and involved in invasive growth in non small cell lung cancer. PLOS ONE 2013; 8: e84944.

16 Cadigan KM, Liu YI. Wnt signaling: complexity at the surface. J Cell Sci 2006; 119: 395-402.

17 Semenov MV, Tamai K, Brott BK, Kuhl M, Sokol S, He X. Head inducer Dickkopf-1 is a ligand for Wht coreceptor LRP6. Curr Biol 2001; 11: 951-961.

18 Mao B, Wu W, Davidson G, Marhold J, Li M, Mechler BM et al. Kremen proteins are Dickkopf receptors that regulate wnt/beta-catenin signalling. Nature 2002; 417: 664-667.

19 Kwon SR, Lim MJ, Suh CH, Park SG, Hong YS, Yoon BY et al. Dickkopf-1 level is lower in patients with ankylosing spondylitis than in healthy people and is not influenced by anti-tumor necrosis factor therapy. Rheumatol Int 2012; 32: 2523-2527.

20 Wang S, Zhang S. Dickkopf-1 is frequently overexpressed in ovarian serous carcinoma and involved in tumor invasion. Clin Exp Metastasis 2011; 28: 581-591

21 Korkosz M, Gasowski J, Leszczynski P, Pawlak-Bus K, Jeka S, Kucharska E et al. High disease activity in ankylosing spondylitis is associated with increased serum sclerostin level and decreased wingless protein-3a signaling but is not linked with greater structural damage. BMC Musculoskelet Disord 2013; 14: 99.

22 Stroup DF, Berlin JA, Morton SC, Olkin I, Williamson GD, Rennie D et al. Meta-analysis of observational studies in epidemiology: a proposal for reporting. Meta-analysis Of Observational Studies in Epidemiology (MOOSE) group. JAMA 2000; 283: 2008-2012.

23 Zintzaras E, loannidis JP. Heterogeneity testing in meta-analysis of genome searches. Genet Epidemiol 2005; 28: 123-137.
24 Higgins JP, Thompson SG. Quantifying heterogeneity in a meta-analysis. Stat Med 2002; 21: 1539-1558.

25 Shan ZX, Han JX, Cui YZ, Zhou XY, Liu JM. The expression of serum DKK-1 and its significance in patients with ankylosing spondylitis. Med Lab Sci Clin 2011; 22: 1-2,7.

26 Sui L, Zhang K, Wang Y. Clinical significance of serum level of DKK-1 in patients with ankylosing spondylitis. Tianjin Med Journal 2011; 39: 918-920.

27 Liu H, Dong Q. Study on the content of lymphocytes, the expression of DKK1 and BMP-2in patients of ankylosing spondylitis with HLA-B27 positive. Chongqing Med 2012; 41: 3857-3858,3861.

28 Taylan A, Sari I, Akinci B, Bilge S, Kozaci D, Akar S et al. Biomarkers and cytokines of bone turnover: Extensive evaluation in a cohort of patients with ankylosing spondylitis. BMC Musculoskelet Disord 2012; 13: 191.

29 Long L, Liu Y, Wang S, Zhao Y, Guo J, Yu P et al. Dickkopf-1 as potential biomarker to evaluate bone erosion in systemic lupus erythematosus. J Clin Immunol 2010; 30: 669-675.

30 Diarra D, Stolina M, Polzer K, Zwerina J, Ominsky MS, Dwyer D et al. Dickkopf-1 is a master regulator of joint remodeling. Nat Med 2007; 13: 156-163.

31 Gavriatopoulou M, Dimopoulos MA, Christoulas D, Migkou M, lakovaki M, Gkotzamanidou $\mathrm{M}$ et al. Dickkopf-1: a suitable target for the management of myeloma bone disease. Expert Opin Ther Targets 2009; 13: 839-848.

32 Heath DJ, Chantry AD, Buckle CH, Coulton L, Shaughnessy JD Jr, Evans HR et al. Inhibiting Dickkopf-1 (DKK1) removes suppression of bone formation and prevents the development of osteolytic bone disease in multiple myeloma. J Bone Min Res 2009; 24: 425-436.

33 Pinzone JJ, Hall BM, Thudi NK, Vonau M, Qiang YW, Rosol TJ et al. The role of Dickkopf-1 in bone development, homeostasis, and disease. Blood 2009; 113: 517-525.

34 Cortes A, Maksymowych WP, Wordsworth BP, Inman RD, Danoy P, Rahman $P$ et al. Association study of genes related to bone formation and resorption and the extent of radiographic change in ankylosing spondylitis. Ann Rheum Dis 2015; 74: 1387-1393.

35 Ahmed SF, Fouda N, Abbas AA. Serum Dickkopf-1 level in postmenopausal females: correlation with bone mineral density and serum biochemical markers. J Osteoporos 2013; 2013: 460210.

This work is licensed under a Creative Commons Attribution-NonCommercial-NoDerivs 4.0 International License. The images or other third party material in this article are included in the article's Creative Commons license, unless indicated otherwise in the credit line; if the material is not included under the Creative Commons license, users will need to obtain permission from the license holder to reproduce the material. To view a copy of this license, visit http://creativecommons.org/licenses/by-nc-nd/4.0/ 